\title{
Study of Socio-economic and Psychological Characteristics of Farmers towards Climate Change
}

\author{
Pankaj Kumar Meghwal ${ }^{1 *}$, Rajkumar Josmee Singh², Muthu Lakshmi B. ${ }^{2}$, Inne Lego ${ }^{2}$ and Konjengbam Monika Devi ${ }^{2}$
}

${ }^{1}$ Dept. of Agricultural Extension, College of Agriculture, Junagadh Agricultural University, Junagadh, Gujarat (362 001), India

${ }^{2}$ Agricultural Extension, School of Social Sciences, College of Post-Graduate Studies, Barapani, Meghalaya (793 102), India

\section{Corresponding Author}

Pankaj Kumar Meghwal

e-mail: pankaj_00982@yahoo.com

\author{
Article History \\ Article ID: 3 C0191 \\ Received in $18^{\text {th }}$ September, 2017 \\ Received in revised form $19^{\text {th }}$ October, 2017 \\ Accepted in final form $28^{\text {th }}$ November, 2017
}

\begin{abstract}
A study was carried out to study the socio-economic and psychological profile of Climate Change Vulnerable Farmers in agriculture. The state of Madhya Pradesh (MP) has reasons to be concerned about climate change, as the state has a large population dependent on agriculture and forests for livelihood and its economy is also dependent on agriculture and natural resources and any adverse impact on these and allied sectors will negate the efforts to alleviate poverty and ensure sustainable livelihood for the population. Keeping in view the above specifications the following research objective was framed viz. To study personal, socio-economic and psychological characteristics of farmers. The study followed exploratory research design. Mixed-method sampling procedure was followed. The study had been conducted at Manasa block of Neemuch district and Malhargarh block of Mandsaur district of Madhya Pradesh. Two villages were selected purposively from each of the selected blocks thereby constituting four villages for the study. A total of 60 farmers were selected by way of proportionate random sampling method. The data collected were processed and analysed using statistical tools such as frequency, percentage, mean and standard deviation. With regards to 'Decision-Making on Adoption of Mitigation and Adaptation Practices of Climate Change Practices in Agriculture,' it was revealed that majority of the respondents i.e. $70.00 \%$ belonged to category of high level of Decision-making followed by $18.33 \%$ and $11.66 \%$ who belonged to categories of medium and low level of Decision-Making on adoption of mitigation and adaptation practices of climate change practices in agriculture respectively.
\end{abstract}

Keywords: Climate change, socio-economic, psychological, sampling

\section{Introduction}

Climate change is a global phenomenon, although its impacts are regional, making some regions more vulnerable than the others. Our world is characterized by fast moving geopolitical and natural changes and the scenarios drawn by climate change specialists are alarming (Dympep et al., 2016). Because of climate change, economic growth of the countries heavily dependent on their agricultural system is getting compromised. Climate change is causing far-reaching impact on not only the socio-economic domain of the nations but also dampening the age-old socio-cultural and demographic systems of those countries (Bharti and Indoria, 2017).

India is facing the challenges of sustaining its rapid agricultural growth while dealing with the global threat of climate ch ange. The first strategy is to mitigate/reduce the rate and magnitude of climate change itself through reducing the emissions of human causes of climate change and the second (and complementary) option is to promote adaptation to climate change to decrease the impacts and take advantage of new opportunities (Meghwal et al., 2016). The state of Madhya Pradesh has reasons to be concerned about climate change, as the state has a large population dependent on agriculture and forests for livelihood and its economy is also dependent on agriculture and natural resources and any adverse impact on these and allied sectors will negate the efforts to alleviate poverty and ensure sustainable livelihood for the population (MP SAPCC, 2014).

Socio-economic status of the individuals is the combination of the measurements of economic and social positions of an individual or groups in relation to others in the society (Ahirwar et al., 2016). Decision making in a changing climate requires new areas of expertise and wider consultation than might typically be involved in traditional "development decision-making," given both the cross-sectoral nature of climate change impacts and the uncertainty regarding the level of climate change and climate variability (Meghwal et al., 2017a).

\section{Materials and Methods}

The study followed exploratory research design. Mixedmethod sampling procedure was followed. The study had been conducted at Manasa block of Neemuch district and 
Malhargarh block of Mandsaur district of Madhya Pradesh. Two villages were selected purposively from each of the selected blocks thereby constituting four villages for the study. A total of 60 farmers were selected by way of proportionate random sampling method. Considering the objectives of the study, 10 independent variables and a dependent variable were identified based on extensive review of literature and also in consultation with experts. The selected variables were quantified with the help of available measurement procedures. The data collected were processed and analysed using statistical tools such as frequency, percentage, mean and standard deviation. The distributions of scores were checked for normality by using one sample test of Kurtosis \& Skewness.

\section{Results and Discussion}

Results have been discussed under the following heads

\subsection{Personal, socio-economic characteristics}

\subsubsection{Age}

It could be revealed from the Table 1 that more than half of the respondents (51.67\%) belonged to young age group (<36 years) followed by $35.00 \%$ and $13.33 \%$ of respondents who are in middle age ( $36-55$ years) and old age group (>55 years) respectively. During the data collection it was observed that agriculture in the study area was entrepreneuring and challenging, this might be the reason where young farmers have smartly taken up agriculture/farming as their occupation. The present findings did not correspond to the findings of

Table 1: Distribution of respondents according to socioeconomic characteristics

\begin{tabular}{lllcc}
\hline $\begin{array}{l}\text { S I. } \\
\text { No. }\end{array}$ & Variable & Category & $\begin{array}{c}\text { Fre- } \\
\text { quency }\end{array}$ & $\begin{array}{c}\text { Percent- } \\
\text { age }\end{array}$ \\
\hline 1. & Age & Young age group & 31 & 51.67 \\
& & Middle age group & 21 & 35.00 \\
& & Old age group & 8 & 13.33 \\
2. & Level of & Illiterate & 3 & 5.00 \\
& education & Primary school & 16 & 26.67 \\
& & Middle school & 17 & 28.33 \\
& & High school & 13 & 21.67 \\
& & Higher secondary & 4 & 6.67 \\
& & Graduate & 7 & 11.66 \\
3. & Annual & Low annual income & 44 & 73.34 \\
& income & Middle annual in- & 14 & 23.33 \\
& & come & & \\
& & High annual income & 2 & 3.33 \\
& & Marginal farmers & 24 & 40.00 \\
& Op- & Small farmers & 14 & 23.33 \\
& land & Semi-medium & 15 & 25.00 \\
& & Medium farmers & 7 & 11.67 \\
\hline
\end{tabular}

Adewale (2012), Berg (2013), Mohanraj \& Karthikeyan (2014), Neethi (2014) and Umar et al. (2015).

\subsubsection{Level of education}

The highest percentage (28.33\%) amongst the respondents had middle level of schooling. Remaining of the respondents had education up to primary, high school, higher secondary and graduate with $26.67 \%, 21.67 \%, 6.67 \%$ and $11.66 \%$ respectively. There was only $5.00 \%$ of respondents who were illiterate. In the light of the above result, lack of awareness on need for education, poor intervention of educational programmes in the study area by state and central governments, improper and inadequate educational facilities in the rural areas etc. might be the startling reasons for the above findings. Also, poor marginal and small farmers could not go for higher studies and at the same time they could not send their children for pursuing higher education. Ogunleye and Yekinni (2012); Rakgase and Norris (2014) had similar findings as above, conversely the findings of Agbongiarhuoyi et al. (2013), Mohanraj and Karthikeyan (2014); Neethi (2014) were found to be contradictory.

\subsubsection{Annual income}

Three fourth of respondents (73.34\%) belonged to Low Annual Income group and this is followed by $23.33 \%$ and $3.33 \%$ of them who belonged to Medium Annual Income and High Annual Income group respectively. The core probable reason for majority of the respondents/farmers earn less income might be due to improper crop planning, where in updated cropping calendar should be followed in purview of climate variability. The subsistence farming being prevailed coupled with deprived market linkages and poor supply chain of agricultural produces in the villages were some noticeable concrete reasons for this lopsided distribution of respondents. This finding was in consonance with the findings of Berg (2013) and it was inconsonance with those findings of Shashidhara (2006), Kharumnuid (2011); Mohanraj and Karthikeyan (2014); Neethi (2014).

\subsubsection{Operational land holding}

Higher percentage; exactly forty per cent $(40.00 \%)$ of the respondents were marginal farmers. The following percentage of $25.00 \%, 23.33 \%$ and $11.67 \%$ of respondents belonged to Semi-medium, Small and Medium farmers respectively. The above findings commented that population had increased day by day resulting to fragmentation in ownership. It was also observed that fast urbanisation and industrialization has encroached agricultural land thereby diminishing the available agricultural land. The findings of the present study corroborated with the findings of Shadap (2014) but not with findings of Idrisa et al. (2012); Agbongiarhuoyi et al. (2013), Sushant (2013); Campos et al. (2014); Neethi (2014).

\subsection{Psychological characteristics}

\subsubsection{Knowledge on mitigation and adaptation practices}

A perusal of Table 2, could revealed that more than half i.e., $55.00 \%$ of respondents belonged to group who had medium level of knowledge on mitigation and adaptation 
Table 2: Distributions of respondents according to Psychological Characteristics

\begin{tabular}{lllcc}
\hline SI. & Variable & $\begin{array}{l}\text { Cat- } \\
\text { No. }\end{array}$ & $\begin{array}{c}\text { Fre- } \\
\text { quency }\end{array}$ & $\begin{array}{c}\text { Per- } \\
\text { centage }\end{array}$ \\
\hline 1. & Knowledge on mitiga- & Low & 12 & 20.00 \\
& tion and adaptation & Medium & 33 & 55.00 \\
& practices & High & 15 & 25.00 \\
2. & Risk orientation & Low & 5 & 8.33 \\
& & Medium & 50 & 83.34 \\
3. & Social cohesiveness & High & 5 & 8.33 \\
& & Low & 42 & 70.00 \\
& & Medium & 1 & 1.67 \\
4. & Awareness on con- & 17 & 28.33 \\
& sequences of climate & Medium & 38 & 3.33 \\
& change in agriculture & High & 20 & 33.34 \\
5. & Perception on climate & Low & 31 & 51.67 \\
& change & Medium & 28 & 46.67 \\
& & High & 1 & 1.66 \\
6. & Fatalism & Low & 40 & 66.67 \\
& & Medium & 2 & 3.33 \\
& Digh & 18 & 30.00 \\
7. & Decision-making on & Low & 7 & 11.67 \\
adoption of mitigation & Medium & 11 & 18.33 \\
and adaptation prac- & High & 42 & 70.00 \\
practices in agriculture & & & \\
\hline
\end{tabular}

practices. Subsequently, one fourth $(25.00 \%)$ and one fifth (20.00\%) of respondents belonged to group who had high and low level of knowledge on mitigation and adaptation practices respectively. The present percentage distribution of respondents might be due to keenness of farmers to seek more information from possible sources of information such as State Deptt. of Agri. \& Hort., KVK, Co-operative Societies and sharing cognate and connate knowledge amongst them, as it was observed during the interview of respondents. The present findings were in agreement with the findings of Claessens et al. (2012); Esham and Garforth (2013), Hibbs et al. (2014) and Marshall et al. (2014). However, Ogunleye and Yekinni (2012) had commented differently.

\subsubsection{Risk orientation}

Majority i.e. $83.34 \%$ of the respondents had medium orientation towards risk and uncertainty associated with farming due to climate change. Equal percentage of $8.33 \%$ of the respondents had low and high level of risk orientation. Since the farmers had exposed to agricultural farming systems which were moderate and highly vulnerable, they were moderately attuned towards risk orientation on climate variability and its consequences. However, appropriate extension strategies need to be administered in order to highly orient the farmers towards risks associated with climate change in agriculture and allied activities. These findings corroborated with the findings of Shashidhara (2006), Gajendra (2011), Mohanraj \& Karthikeyan (2014) and Shadap (2014).

\subsubsection{Social cohesiveness}

It could be narrated that majority i.e., $70.00 \%$ of respondents had low level of social cohesiveness, followed by $28.33 \%$ and $1.67 \%$ of the respondents who belonged to high and medium level of social cohesiveness group respectively. Such highly lopsided distribution on low or weak social cohesiveness might be due to derange social initiatives and less information seeking behaviour of respondents on meeting challenges against climate change. Startling reasons for low social cohesiveness might be due to less higher education rate of the respondents which in turn could not perceive the issues of climate change in agriculture a social issue. The present finding supported the conclusions drawn by Nadre (2000) but contradicted the conclusions drawn by Palmurugan et al. (2006); Mohanraj \& Karthikeyan (2014); Neethi (2014) and Shadap (2014).

\subsubsection{Awareness on consequences of climate change in agriculture}

It could be revealed that majority of respondents i.e. $63.34 \%$ had medium level of awareness followed by $33.33 \%$ and $3.33 \%$ of the respondents who had high and low level of awareness respectively. The possession of medium level of awareness by the respondents might be due to recent interventions of government initiatives such as 'Mera Gaon Mera Gaurav (MGMG)' through State Deptt. of Agriculture, Agri., \& Hort. Colleges, KVKs etc. Intervention of crop insurance and its wide dissemination in the villages might be a valid reason behind the prevalence the present distribution of level of awareness. The observations of the present study corroborated with the observations made by Idrisa et al. (2012); Shadap (2014), however Rosenzweig et al. (2007); Verchot et al. (2007), Hertel and Rosch (2010); Ogunleye and Yekinni (2012) had observed differently.

\subsubsection{Perception on climate change}

It could be clearly commented that about fifty per cent $(51.67 \%)$ of the respondents had low level of perception on climate change followed by $46.67 \%$ and negligible per cent of $1.66 \%$ of the respondents who had medium and high level of perception on climate change respectively. During the discourse of study, it was noted from the respondents that concrete evidences about consequences on climate change in agriculture was strongly dialogued. Occurrence of erratic pest and diseases attacks in crops and animal, dry spells of rain followed by prolonged drought, increase in day and night temperatures etc. were main observations placed by half of the respondents as consequences of climate change. However, hefty section of farmers commented that until they saw they didn't believe. Hence the above explanation paroles 
well with the findings of the study. This finding corroborated with the findings of Sahu and Mishra (2013) but not in line with findings Campos et al. (2014); Dang et al. (2014); Hibbs et al. (2014).

\subsubsection{Fatalism}

Majority of the respondents i.e. $66.67 \%$ belonged to low level of fatalism, followed by $30.00 \%$ and $3.33 \%$ who belonged to high and medium level respectively. Explanation of this findings might augur well when the findings of knowledge and awareness levels were kept in due considerations. As farmers' knowledge and awareness on climate change stood well, the exposition on fate and belief diminished. During the survey at different villages in the study, it was clearly observed that farmers availed crop insurances from co-operative societies, financial institutions etc. which was a token of contingency for crop failure due to climate change. These findings are in consonance with the findings of Grothmann and Patt (2005), Esham and Garforth (2013) and Nkwusi et al. (2015). Dissimilar results had been reported from Dang et al. (2014) and Liu et al. (2014).

3.3. Decision-making on adoption of mitigation and adaptation practices of climate change practices in agriculture

It could be clearly divulged from data that majority of the respondents i.e. $70.00 \%$ belonged to category of high level of Decision-making followed by $18.33 \%$ and $11.67 \%$ who belonged to categories of medium and low level of DecisionMaking on adoption of mitigation and adaptation practices of climate change practices in agriculture respectively. The conceivable reason for the above findings might be due to considerable awareness of the farmers on negative consequences of climate change in agriculture, good knowledge on mitigation and adaptation of agricultural practices on climate change, appropriate orientation of majority of farmers on climate change associated risks followed by low fatalistic nature of respondents in relation to climate change impacts on agriculture. The accumulation of such factors along with active interactions and interventions of stakeholders, for example, extension agents from state departments of agriculture and horticulture, KVK personnel, members of co-operative societies etc. along with farmers on climate change mitigation and adaptation enabled the respondents better decision makers (Meghwal et al., 2017b). These findings were in consonance with the results of Ugwoke et al. (2012); Tologbonse et al. (2010); Hellin et al. (2014); Varadan and Kumar (2014).

\section{Conclusion}

More than half of the respondents belonged to young age group, the highest percentage amongst the respondents had middle level of schooling, three fourth of respondents belonged to Low Annual Income group and higher percentage; exactly forty per cent of the respondents were marginal farmers. With regards to 'Decision-Making,' it was revealed that majority of the respondents belonged to category of high level of Decision-Making on adoption of mitigation and adaptation practices of climate change practices in agriculture.

\section{References}

Adewale, A.O., 2012. Assessment of poor resource farmers' level of awareness on climate change and adaptation/ mitigation strategies in some selected rural areas in Oya state, Southwest, Nigeria. Journal of Earth Sciences 1(2), 57-61.

Agbongiarhuoyi, A.E., Abdulkarim, I.F., Fawole, O.P., Obatolu, B.O., Famuyiwa, B.S., Oloyede, A.A., 2013. Analysis of farmers' adaptation strategies to climate change in cocoa production in Kwara state. Journal of Agricultural Extension 17(1), 10-22.

Ahirwar, M.K., Singh, H.S., Patel, R.K., Mondal, M.K., 2016. Socio-personal and economic profile of peri-urban and rural dairy farmers in rewa district of madhya pradesh. International Journal of Agriculture Sciences 8(63), 3548-3551.

Berg, J.V.D., 2013. Socio-economic factors affecting adoption of improved agricultural practices by small scale farmers in South Africa. African Journal of Agricultural Research 8(35), 4490-4500.

Bharti, Indoria, D., 2017. Awareness about the impact of climate change on agriculture in traditional agriculture: a gender based comparative study. Indian Research Journal of Extension Education 17(1), 94-99.

Campos, M., Velazquez, A., McCall, M., 2014. Adaptation strategies to climatic variability: a case study of smallscale farmers in rural Mexico. Land Use Policy 38, 533-540.

Claessens, L., Antle, J.M., Stoorvogel, J.J., Valdivia, R.O., Thornton, P.K., Herrero, M., 2012. A method for evaluating climate change adaptation strategies for small-scale farmers using survey, experimental and modeled data. Agricultural Systems 111, 85-95.

Dang, H.L., Li, E., Bruwer, J., Nuberg, I., 2014. Farmers' perceptions of climate variability and barriers to adaptation: lessons learned from an exploratory study in Vietnam. Mitigation and Adaptation Strategies for Global Change 19, 531-548.

Dympep, A., Singh, R.J., Chauhan, J., Pandey, D.K., Hemochandra, L., 2016. Standardize index for measuring performance of farmers on mitigation and adaptation practices of climate change. Indian Research Journal of Extension Education 16(3), 93-96.

Esham, M., Garforth, C., 2013. Agricultural adaptation to climate change: insights from a farming community in Sri Lanka. Mitigation and Adaptation Strategies for Global Change 18, 535-549.

Gajendra, T.H., 2011. Perspectives of farmers on effect of climate change on agriculture and livestock. M.Sc. Thesis, submitted to university of agricultural sciences, Dharwad, Karnataka, India.

Grothmann, T., Patt, A., 2005. Adaptive capacity and human cognition: the process of individual adaptation to climate change. Global Environmental Change 15(3), 199-213. 
Hellin, J., Bellon, M.R., Hearne, S.J., 2014. Maize landraces and adaptation to climate change in Mexico. Journal of Crop Improvement 28(4), 484-501.

Hertel, T.W., Rosch, S.D., 2010. Climate change, agriculture, and poverty. Applied Economic Perspectives and Policy. doi:10.1093/aepp/ppq016.

Hibbs, A.C., Kahl, D., PytlikZillig, L., Champion, B., Monem, T.A., Steffensmeier, T., Rice, C.W., Hubbard, K., 2014. Agricultural producer perceptions of climate change and climate education needs for the central great plains. Journal of Extension 52(3), 1-10.

Idrisa, Y.L., Ogunbameru, B.O., Ibrahim, A.A., Bawa, D.B., 2012. Analysis of awareness and adaptation to climate change among farmers in the sahel savannaagroecological zone of Borno state, Nigeria. African Journal of Agricultural Research 7(25), 3632-3637.

Kharumnuid, P., 2011. A study on the perception and adaptation of potato growers to climate change in east khasi hills district of meghalaya. M.Sc. Thesis, Submitted to Acharya N.G. Ranga Agricultural University, Hyderabad, Andhra Pradesh, India.

Liu, Z., Smith, W.J., Safi, A.S., 2014. Rancher and farmer perceptions of climate change in nevada, USA. Climatic Change 122, 313-327.

Marshall, N.A., Dowd, A.M., Fleming, A., Gambley, C., Howden, M., Jakku, E., Larsen, C., Marshall, P.A., Moon, K., Park, S., Thorburn, P.J., 2014. Transformational capacity in australian peanut farmers for better climate adaptation. Agronomy for Sustainable Development 34, 583-591.

Meghwal, P.K., Singh, R.J., Singh, R., 2017a. A multinomial logistic regression on farmers' decision on technology adaptation for nutrition-sensitive climate change vulnerable agriculture. Indian Research Journal of Extension Education 17(3), 7-9.

Meghwal, P.K., Singh, R.J., Singh, R., 2017b. Farmers' mitigation and adaptation of climate change: a stakeholder analysis. Lap lambert academic publishing, Republic of Moldova.

Meghwal, P.K., Singh, R.J., Pandey, D.K., Singh, R., Jadav, N.B., Rajput, R.P., 2016. Problems faced by the farmers in adoption of mitigation and adaptation of climate change practices in agriculture. International Journal of Agriculture Sciences 8(56), 3086-3088.

Mohanraj, K., Karthikeyan, C., 2014. Socio economic characteristics of tank irrigated farmers in Tamil Nadu. Trends in Biosciences 7(19), 2995-2998.

MP SAPCC., 2014. State action plan on climate change: Madhya Pradesh, Government of Madhya Pradesh.

Nadre, K.R., 2000. A study on constraints in adoption of recommended practices of cotton in aurangabad and jalnadistrict. MANAGE Extension Research Review 1(2), 66-76.

Neethi, B., 2014. Study of socio-economic profile of farmers in mahabubnagar district of Andhra Pradesh. Global Journal for Research Analysis 3(8), 4-7.
Nkwusi, G., Adeaga, S., Ayejuyo, S., Annuk, A., 2015. Climate change; farmers' awareness, perceptions and responses in lagos state. Applied Ecology and Environmental Sciences 3(4), 95-99.

Ogunleye, K.Y., Yekinni, O.T., 2012. Crop farmers' knowledge level of climate change in iiorin east local government area of Nigeria. Developing Countries Studies 2(7), 6-13.

Palmurugan, M., Jhamtani, A., Padaria, R.N., 2006. Entrepreneurial behavior of Vanilla growers of Tamil Nadu and Kerala. Pusa Agri Science 29, 76-83.

Rakgase, M., Norris, D., 2014. Factors that influence choice of drought coping strategies in limpopo province, South Africa. Journal of Human Ecology 47(2), 111--116.

Rosenzweig, C., Major, D.C., Demong, K., Stanton, C., Horton, R., Stults, M., 2007. Managing climate change risks in New York city's water system: assessment and adaptation planning. Mitigation and Adaptation Strategies for Global Change 12, 1391-1409.

Sahu, N.C., Mishra, D., 2013. Analysis of perception and adaptability strategies of the farmers to climate change in Odisha, India. APCBEE Procedia 5, 123-127.

Shadap, M.D., 2014. Contextual vulnerability of climate change in agriculture: an agro-climatic zones analysis in Meghalaya. M.Sc. Thesis, Submitted to Central Agricultural University, Imphal, India.

Shashidhara, K.K., 2006. A study on management of ecofriendly practices by vegetable growers of north Karnataka. Ph.D. Thesis, Submitted to University of Agricultural Sciences, Dharwad.

Sushant, 2013. Impact of climate change in eastern Madhya Pradesh, India. Mongabay.com Open Access Journal. Tropical Conservation Science 6(3), 338-364.

Tologbonse, E.B., Auta,S.J., Bidoli, T.D., Jaliya M.M, Onu, R.O., Issa F.O., 2010. Farmers' perception of the effects of climate change and coping strategies in three agroecological zones of Nigeria. Journal of Agricultural Extension 14(1), 125-136.

Ugwoke, F.O., Nnadi, F.N., Anaeto, C.F., Aja, O.O., Nwakwasi, R.N., 2012. Crop farmers' perception of and adaptation to climate change in orlu agricultural zone of imo state, Nigeria. Journal of Agricultural Extension 16(2), 212-223.

Umar, I., Isah, A.D., Bello, A.G., Abubakar, B.Z., 2015. Farmers' perception on climate change in Sokoto state, Nigeria. African Journal of Agricultural Research 10(11), 12881294.

Varadan, R.J., Kumar, P., 2014. Indigenous knowledge about climate change: validating the perceptions of dryland farmers in Tamil Nadu. Indian Journal of Traditional Knowledge 13(2), 390-397.

Verchot, L.V., Noordwijk, M.V., Kandji, S., Tomich, T., Ong, C., Albrecht, A., Mackensen, J., Bantilan, C., Anupama, K.V., Palm, C., 2007. Climate change: linking adaptation and mitigation through agroforestry. Mitigation and Adaptation Strategies for Global Change 12, 901-918. 